of the Lister Institute has given the value of 0.7 $\mathrm{gm}$./gm., or identical with that obtained microbiologically.

Beer is a good source not only of riboflavin but also of nicotinic acid (of the order of $15 \mu \mathrm{gm} . / \mathrm{c.c}$. ), and it is also a reasonable assumption that it contains appre. ciable amounts of other recently identified nutrients, such as biotin, pantothenic acid and inositol. As regards the latter, there is appreciable destruction of phytic acid during germination, with a corresponding increase in the amount of inositol present. Thus in a sample of malted English wheat the phytate phosphorus was found to be $190 \mathrm{mgm}$. per cent as against an average figure of $270 \mathrm{mgm}$. before germination. In passing, we cannot refrain from directing attention to these new aspects of the nutritional merits of that popular lunch-bread, cheese and beer.

Brewed vinegars are also of interest in this connexion, and in the case of riboflavin have been found to have a content of approximately $0.7 \mu \mathrm{gm} . / \mathrm{c} . c$. Artificial vinegars, as would be expected from their composition, contain no nutrient materials.

The riboflavin content of beer seems to provide part of the explanation of the relative rarity in Great Britain of clear-cut symptoms of deficiency conditions. This is in striking contrast to what is seen in the United States and Canada. When Dr. V. P. Sydenstricker, one of the leading authorities on riboflavin and other deficiency conditions, was in England a short time ago, he was greatly impressed by the contrast but he found it difficult to give a plausible explanation. Beer drinking does not provide a com. plete answer, because there is no evidence that abstainers show a high incidence of signs of riboflavin deficiency. When one of us (J.C. D.) was recently in Washington, Dr. W. H. Sebrell informed him that he had obtained evidence of the presence of appreciable amounts of riboflavin in tea. This has been followed up with the following results, obtained on a few samples.

$$
\begin{array}{lcccc} 
& & & & \mu \mathrm{gm} \text {. per gm. } \\
\text { Tea } & \ldots & \ldots & \ldots & 9 \cdot 0 \\
\text { Coffee } & \ldots & \ldots & \ldots & 1 \cdot 7 \\
\text { Cocoa } & . & . & . & 2 \cdot 7
\end{array}
$$

These figures indicate that an amount of the order of $10 \mu \mathrm{gm}$. of riboflavin might be provided by a breakfast cup of tea. The daily quantity would certainly not be negligible in the case of the habitual tea drinker.

Following the same line of reasoning that led to the re-examination of beer, it was thought desirable to analyse commercial meat extracts. For a long time these have been dismissed by nutrition experts as of little or no value as foods. Lean meat is, however, a good source of nicotinic acid and contains an appreciable amount of riboflavin. Consideration of the methods of manufacturing meat extracts suggests that there would be considerable leaching out of these vitamins into the extract. This appears to be the case, since five well-known proprietary brands of meat extract gave riboflavin and nicotinic acid values in the ranges of $15 \cdot 4-25 \cdot 8$ and 410 $1,025 \mu \mathrm{gm} . / \mathrm{gm}$. respectively. A breakfast cup of these extracts would provide on the average $0.2 \mathrm{mgm}$. of riboflavin and $7 \mathrm{mgm}$. nicotinic acid. These quantities are by no means insignificant.

It is possible that the relatively high nicotinic acid content of meat extracts may prove to be related to their reputation as stimulants. The recent work of Frankau is of interest in this connexion.
The experimental results reported above are only preliminary, but they are clearly of importance not only in connexion with an accurate assessment of our overall intake of nutrients but also in indicating fruitful lines of research in malting and food processing generally. It is certain that in brewing research in the future, stress will be laid on the conditions of malting and mashing that will give the maximum production of vitamins consistent with other requirements in the brewing process. Malted cereals would indeed appear to be deserving of the most careful study. Malt. extracts may appear in a now light. Examination of a random concentrated sample gave a value indicating a riboflavin content of $8 \mu \mathrm{gm}$. per gm.; the nicotinic acid content will be correspondingly high. Malt products may, therefore, be of considerable importance as ingredients in bread and such products as breakfast foods, chick foods, otc.

Meat extracts are only half the story of meat processing; any concentration of vitamins in extracts means a corresponding poverty in corned beef. Likewise the inclusion before the completion of the process of any material extracted in the preliminary treatment of meat before drying is desirable not only on grounds of palatability but also of nutritive value.

This communication refers mainly to work being carried out at the Cereals Research Station of the Ministry of Food, St. Albans, particularly by Drs. E. C. Barton-Wright and R. G. Booth. Full details of this work will shortly be published.

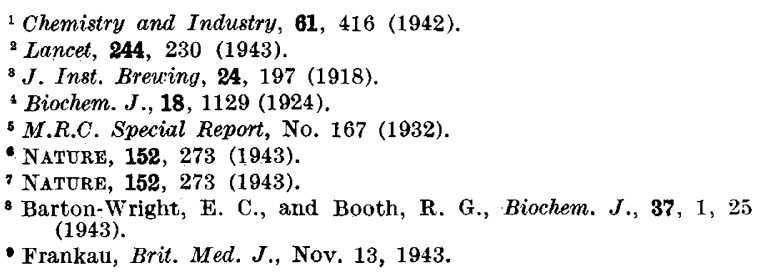

\section{PRESERVATION OF FOODS BY DRYING}

\author{
By $D_{R}$ FRANKLIN KIDD \\ Superintendent, Low Temperature Research Station,
Cambridge
}

RIED foods as a war development have been well advertised, particularly in the United States of America. With the exception of dried egg and dried skim milk ('household milk'), they have not, however, been on sale to the general public in Great Britain. The intelligent layman, therefore, in view of what he has been told through the Press about the exceptionally good quality of dried foods which modern science and technology have been able to achieve, although probably sceptical, would naturally like to try them.

An account appeared in NATURE of August 22, 1942, of a joint meeting of the Nutrition Society and of the Food Group of the Society of Chemical Industry at which the Department of Scientific and Industrial Research demonstrated the results achieved by British science during the War in improving the quality of dried foods. Dried vegetables-potato, cabbage, onions, swede-dried meat, dried egg, dried fish, dried milk and dried soups were served at lunchtime for appraisal by some hundreds of scientific and 
technical workers present on that occasion. It was understood that the manufacture of products of corresponding quality was being actively developed.

Considerable interest is attached, therefore, to a recent lecture on the "Preservation of Foods by Dry. ing" by Sir Joseph Barcroft, chairman of the Food Investigation Board of the Department of Scientific and Industrial Research, delivered at the Royal Institution on November 26.

Sir Joseph apologized at the outset for turning the lecture hall of the Royal Institution into something strongly resembling a kitchen, but aptly quoted from the original documents of the foundation, which described its objects as "for bettering the condition and increasing the comforts of the poor" by, among other things, "teaching ... the application of science to the common purpose of life". There may be prejudice, he said, against dried foods. There is only one really adequate way to test dried foods, and that is to eat them. The pièce de résistance offered to the audience was a large shepherd's pie made on the demonstration bench from dried meat, dried potato, dried onion and dried milk, by Mrs. Edkins, reader in physiology in the University of London, and cooked during the lecture in Lady Dale's oven in the residency of the Director of the Institute. The audience accepted Sir Joseph's advice, and the observer records that nothing eventually remained but the dish.

In many instances acceptability to the palate has turned out to be a good criterion of nutritive value. In the case of milk and vegetables-and Sir Joseph thinks the same might be said of fish and meat-if the taste of the food is such as to make an appeal to the palate, the nutritive value of the food is largely unimpaired, and this to a physiologist with a nineteenth century background is not a little gratifying.

The drying of food aims at defeating both 'time' and 'space'. With regard to 'space', drying, combined with the process known as blocking, reduces the weight and volume of food to something like one eighth of the original. The actual reduction varies from food to food and is summarized in the accompanying table.

The same table shows how far drying combined with proper packaging and storage turns perishables into non-perishables, and so frees distribution from narrow and hampering time limits. But time is also defeated in another sense, that is, in the household, by the ready-to-eat or nearly ready-to-eat nature of the foods.

The world is shrinking. Each of us has less room and fewer hands at his disposal. Nowhere is this more important than in the kitchen. Silent forces are all the time impelling modern man to reduce his food,

Attainable saving calculated as between the most compact form and the form in which the commodity is most usually carried and the attainable storage time after which the food is still in excellent condition, in gas-pack if necessary.

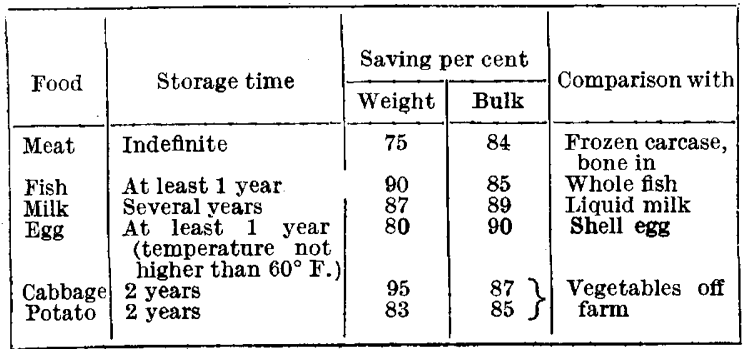

while retaining to the full its palatability and nutritive value, to a form occupying the smallest possible space, having the least possible weight, keeping for the longest possible time and, above all, being as near as may be ready to serve and eat.

In the sense of being ready-to-eat and having a long storage-life dried foods are alternative to canned foods. With both, refrigeration is unnecessary. Canning has had most astonishing successes; it rernains to be seen whether drying, under the acid test of use in war and afterwards in peace, will be able to emulate these successes.

During the lecture the following commodities were rlealt with in turn, particular emphasis being placed on the properties enumerated above-retention of rutritive value and palatability, ease of preparation, saving in weight and space and storage life. The commodities were meat, fish, vegetables (various), eggs and milk. These commodities, with the exception of fish, are now all in production, specially tuned up in the light of recent discoveries, for the needs of the War. In all cases it was pointed out that drying as a process is nothing new to human art; what is new is the retention of quality : dried meat, among clried foods, is the latest arrival. Dried eggs, vegetables, and also dried milk have been known to com. merce since the War of 1914-18.

Meat.-Fresh meat is cut into small pieces, and dried in a current of hot air, after being heated for a short time to $100^{\circ} \mathrm{C}$. For the full flavour of the meat all the juices escaping in cooking must be returned prior to drying, and the temperature of the drying in warm air must be carefully controlled. These are the main provisos. The quality of the product afterwards reconstituted and cooked is little, if any, inferior to that of meat which has not been dried.

The product is a uniform one, and objective standards of quality can be set for various properties, flavour, consistency, nutritive value, fat content, freedom from bacterial contamination, etc.

Above all, dried meat, as to-day defined, is whole meat, nothing having been taken out in the process of preparation except water. The cooking is simply throwing the meat into hot water and cooking immediately, the time taken being that corresponding to the time taken for fresh meat. It is possible to make any dish which requires meat reduced to a mince or to small pieces.

Fish.-Fresh fish is dried in a very similar way to meat. In the case of fish, however, both the proteins and the fats are of a more delicate and labile nature. It had at first been thought that oily fish would present a difficult problem to the dehydrator, but experience has shown that this is not in fact so.

The flavour of fish is to some extent a post-mortem development. Sir Joseph described his experience at the Torry Research Station of the Department of Scientific and Industrial Research, of what he described as a spectrum of fish-cake flavours. Really fresh fish in many cases appears to have very little flavour at all. The fact that herring can be successfully dried may be of importance in the future to the herring industry.

Vegetables.-For drying of vegetables the principle of a pre-drying heat treatment is again used, the destruction of enzymes being of great importance. The savings in weight and bulk are usually most striking ; for example, in the case of cabbage, weight off the farm 25lb., weight of dried material $1 \mathrm{lb}$. The demonstration exhibited a block of dried cabbage 
it was thrown into boiling water, swelled up and was completely cooked in twenty minutes.

There are special difficulties attached to the drying of potato which centre around the fact that the starch grains are gelatinized in the pre-drying heat treatment so that, if the cellulose/cell wall enclosing them is broken, sticky consistency is produced on reconstitution with water.

On the subject of the retention of vitamins, particularly vitamin $\mathrm{C}$ in dried leafy vegetables, an experiment was quoted in which four hundred men were divided into two groups. Cabbage was served as part of a meal; one group had cabbage of good quality bought on the market and cooked in the ordinary way by professional cooks, the other group was given reconstituted dehydrated cabbage, pre. pared by the same cooks. In the result less cabbage was left on the plates of the latter group, and the intake vitamin value was higher in the case of the dried cabbage than in the case of the fresh cabbage.

Milk.-Milk has always presented a difficult problem of storage. The consumer has long known of sweetened condensed milk and unsweetened evaporated mill. In this case the weight of a quart is reduced from something like $41 \mathrm{oz}$. to $17 \mathrm{oz}$. When milk is dried the weight is further reduced to between 5 and 6 oz.

Dried milk can be made which on reconstitution is scarcely, if at all, distinguishable from fresh milk. Further, it can now be stored for periods of up to a year without noticeable change in palatability or nutritive value. Sir Joseph stressed the fact that Britain is a milk-producing country, and that one of our problems had always been that of dealing with the surplus spring and summer milk which is produced in the first flush of the growth of grass. He thinks it has now become possible for the consumer to use the excess of summer milk the following winter.

General Principles.-The general principles whereby high quality is obtained in the drying of food, and the relation between drying and preservation by cold storage in the frozen condition, were briefly sketched. A process of drying foods which has not yet been developed on the commercial scale was referred to, namely, that of evaporating the ice from frozen foods without thawing-the process which is, in fact, now being used for the storage of human plasma and sera for transfusion.

One of the main principles in successful drying is the destruction of enzyme systems by pre-heat treatment; the other is the protection of the dried products from atmospheric humidity and oxygen. Careful control of temperature is always necessary.

Blocking.-On the question of blocking, it was pointed out that in the case of meat the latest development, that is, blocking, has been adopted from the outset. Besides the further saving in volume, blocking has the effect of eliminating oxygen from the pack, which in the case of meat is a hermetically sealed tin. It retards penetration of oxygen if, as in the case of certain other foods, hermetically sealed cans are not used.

Blocks of carrot and cabbage were demonstrated, and it was understood that while most of the preliminary work and development has now been done, blocking has not yet been practised on a large commercial scale except in the case of meat. In the case of dried vegetables which pack very loosely, blocking effects a big further saving in volume.

In the course of his lecture Sir Joseph said that, while he has been for the most part presenting work carried out by the Department of Scientific and Industrial Research on the advice of the Food Investigation Board, and principally at the Low Tem. perature Research Station, Cambridge, he wanted to say that there has been fruitful and active collaboration both with the Agricultural Research Council and the Medical Research Council throughout. The Agricultural Research Council is especially concerned with milk, and the Medical Research Council with the retention of nutritive value.

In the case of all the newly developed foods of high quality, he stressed the fact that this quality is now scientifically ascertainable and statable in objective terms so that a definite standard could be set and insisted on, and the consumer, if necessary, could be protected against exploitation. The principal properties tested at present are palatability, nutritive value and storage life. New techniques are being worked out for assaying palatability. The great development during the last three years of spray. dried egg in the United States and Canada, due to their genius for mass production, has all been sub. jected to rigid quality tests based on the results of researches in which Great Britain had been to a considerable extent the pioneer.

\section{OBITUARY}

\section{Sir Robert Alexander Falconer, K.C.M.G.}

ON November 8, 1943, Sir Robert Falconer was buried from the Convocation Hall of the University of Toronto, over the destinies of which he had presided for twenty-five years. An attack of coronary thrombosis in 1930 impaired his health and compelled him to retire in 1932. His father, a Canadian of Scottish ancestry, was a Presbyterian missionary for some years in Trinidad. Here his son obtained his early education; and from the West Indies won a Gilchrist Scholarship which enabled him to attend the University of Edinburgh. In those days Butcher and Sellar lectured in classics; A. S. Pringle-Pattison in philosophy; David Masson in English literature; and Chrystal and P. G. Tait in mathematics and natural philosophy. Young Falconer graduated with honours in classics and philosophy, and proceeded to the study of theology in Edinburgh, Leipzig, Berlin (under Harnack) and Marburg. He returned to Canada to become at first professor of New Testament Greek, and then principal, of Pine Hill Theological College, Halifax, Nova Scotia. Here he remained until 1907.

In that year Falconer was chosen president of the University of Toronto, which had recently been reorganized by a Royal Commission. This post in a university, which on the arts side included several federated denominational universities and colleges, required great tact, broad interests, good administrative powers and the ability to bring into happy co-operation conflicting interests. This task Sir Robert successfully accomplished. As president his first duty was to administer the new constitution in a period of national expansion. The University grew in numbers, buildings, faculties and departments. The growing needs of Canada were met by increased facilities. After the interval of the War of 1914-18, a new and rapid development followed. The president was quick to recognize and to anticipate public demands for varied types of training at the university level. When he retired in 1932 , the University $c_{0}$ 